\title{
Critical Paths and Sensitivities towards a Zero Emission Vehicle Fleet in Germany A Scenario Based Approach
}

\author{
Bernd Propfe, Stephan A. Schmid, Horst E. Friedrich \\ German Aerospace Center, Institute of Vehicle Concepts
}

Bernd.Propfe@DLR.de

\begin{abstract}
Based on a detailed analysis on how the availability of charging infrastructure influences the technical suitability of electric vehicles for customer needs, we assess critical paths and probable outcomes for the future composition of the German passenger vehicle fleet. In three different market scenarios several technical as well as political options for developing the German market towards a low carbon fleet are analyzed. Eventually, a comparison between the assumptions made and the German political goals regarding the number of electric vehicles on the road is given.
\end{abstract}

\section{INTRODUCTION}

Addressing climate change is one of the great global challenges and has hence become a major political goal. The European Union has confirmed the EU objective to limit global warming to a maximum of $2^{\circ} \mathrm{C}$ compared to preindustrial levels. Since transport emissions make up to a quarter of the overall global $\mathrm{CO}_{2}$-emissions, this sector has a significant influence. Within the EU transport sector, light duty vehicles emitted around $44 \%$ of the entire transport emissions in the year 2000 [1] [2]. Hence, cars are the single most important contributors to the transport GHG emissions. In order to assess the future potential of reducing GHG emissions caused by cars, the DLR Institute of Vehicle Concepts has developed the scenario based simulation model VECTOR21, which is capable of simulating the future German passenger car fleet. By comparing conventional vehicles (e.g. diesel, gasoline) with alternative powertrains (e.g. battery electric vehicles, hybrids, fuel cell vehicles) on a least cost basis, different types of modeled customers choose the best alternative for their specific requirements.

The German government has published a political goal of 1 million electric vehicles on the road by 2020 [3]. In this strategy, electric vehicles are defined as vehicles which are mainly propelled with electricity.

This paper focuses on the analysis of sensitivities resulting from varying scenario assumptions. A special emphasis has been put on the development of charging infrastructure. A newly developed model has been utilized to assess the effect of publicly available charging infrastructure on the (electric) vehicle fleet. Eventually, by simulating the entire German car fleet critical paths towards a low carbon vehicle fleet in Germany have been identified.

\section{The SCENARIO TOOL VECTOR21}

The general idea behind the scenario based simulation tool VECTOR21 is to assess the competition between conventional drive trains and alternative powertrains. Based on a total-cost-of-ownership approach, different technologies and components used in the different types of powertrains are compared. The model considers 3 different vehicle sizes (small, medium, large), each with 10 different types of powertrains (gasoline \& gasoline hybrid, diesel \& diesel hybrid, compressed natural gas (CNG) \& CNG hybrid, plugin-hybrids (PHEV), range-extended electric vehicles (EREV), battery electric vehicles (BEV), and fuel cell vehicles (FCV)).

900 types of customers, defined by their preferences regarding vehicle size, their annual vehicle miles traveled, and their attitude towards alternative drive trains are modeled. For each individual type of customer the purchase cost in combination with the variable cost are calculated depending on the type of powertrain and depending on their individual preferences. The customers then choose the cheapest vehicle which still matches their individual requirements.

In different scenarios, exogenous factors such as raw material costs, technology costs (battery cost, fuel cell cost, costs for electric motors, etc.) as well as political restrictions such as $\mathrm{CO}_{2}$ targets and subsidies can be varied. Eventually, in combination with the pre-defined vehicle concepts and the 900 different types of customers, the market penetration of the future vehicle fleet is calculated. Since each scenario represents a different outcome and hence an alternative future development, the varying results might be interpreted in terms of sensitivities and critical paths. Questions regarding the future market potential of alternative powertrains in the context of varying political and technical developments can be assessed.

The current model has been validated for the German passenger car market using historical data of the penetration of diesel vehicles. For further information on the VECTOR21 model see [4] and [5]. 


\section{INFRASTRUCTURE DEVELOPMENT}

The development of charging and hydrogen infrastructure is considered a crucial parameter for the success of zero emission vehicles. However, it is unclear as to which extend additional infrastructure has to be implemented in order to facilitate the development towards a zero emission fleet.

\section{A. Current Situation in Germany}

As of today, only the eight existing German "modelregions" for electric mobility are equipped with a rather small number of charging stations [6]. Germany has a very reliable electricity grid with less than 15 minutes of outages per year (14.63 minutes in 2009) [7]. Level 2 charging (240 V AC, $16 \mathrm{~A})$ is commonly available. Nevertheless, potential gridwise bottlenecks are currently being accessed very carefully. ${ }^{1}$

Today's situation regarding hydrogen fueling-infrastructure looks less promising: only 8 publicly available fueling stations (and around 30 privately owned) do exist, yet [8]. Recent studies estimate that 3 bn $€$ (approx. 4.4 bn \$) will be necessary for building up of a sufficient, area-covering $\mathrm{H}_{2}$ fueling infrastructure [9]. However, in terms of public funding, the implementation of charging infrastructure imposes the biggest competition for hydrogen fuelinginfrastructure: it is very unlikely, that both competing infrastructure developments will be publicly funded. Hence, detailed assessments regarding both types of infrastructure are necessary. In a long term perspective, hydrogen offers a huge potential for the storage of supplemental renewable energies (esp. off-shore wind) and is hence considered in the long term energy scenarios for Germany [10].

The implementation of fueling infrastructure for compressed natural gas has already been started in Germany in the past. As of today, 870 CNG and/or LPG (liquefied petroleum gas) gas stations have been built up (compared to 14,367 fuel stations in total in 2010) [11].

\section{B. Calculation Model}

In order to combine possible future developments of charging / fueling infrastructure and their effects on the market penetration of zero emission vehicles, new data had to be collected. The current version of VECTOR21 is capable of incorporating the availability of public charging infrastructure as well as (hydrogen) fueling stations. However, so far there has been no data available as to how future infrastructure developments will affect the suitability of electric drive trains regarding customer requirements. A newly developed model based on a comprehensive survey of more than 190,000 trips in Germany has been utilized to assess the impact of different infrastructure scenarios, ranging from only 'charging at home' to an exhaustive public charging infrastructure.

All calculations are based on the survey "Mobilität in Deutschland (MiD) 2008” (mobility in Germany), which

\footnotetext{
${ }^{1}$ The German Government initialized several research projects dealing with the interaction of electric vehicles with the electricity grid.
}

represents the German equivalent to the American "National Household Transportation Survey (NHTS) 2009” [12]. The database consists of more than 34,000 surveyed vehicles in 26,000 households with over 193,000 individual trips. Amongst other details, departing as well as arrival times, trip lengths, trip purposes, and the type of vehicle itself have been recorded.

Our newly developed model assesses the impact of increasingly available charging infrastructure on the suitability of electric vehicles for German driving profiles. Based on detailed state-of-charge (SOC) profiles for each surveyed vehicle, the feasibility of completing the daily trips in an all-electric mode (charge depleting mode) is assessed. In order to calculate the SOC parameters, an algorithm calculating both the minimal feasible SOC as well as the maximal possible SOC has been implemented. The minimal SOC parameter is based on the requirement that the last trip of the day has to be completed. In other words, after having completed the last trip of the day the battery is allowed to be discharged down to its minimal permitted SOC. The maximal possible SOC indicates charging at full power as soon as the vehicle is plugged-in. I.e., this algorithm represents uncontrolled charging.

Connections to the electricity grid are calculated taking into account the purpose of each individual trip. Based on probabilities for finding an unoccupied charging spot at the end of the trip, different scenarios for the implementation of (public) charging infrastructure might be calculated.

Both, the minimal and the maximal SOC are calculated for each surveyed vehicle for every hour of the day. Due to the limited size of the battery in combination with restricted maximal and minimal feasible SOCs, a daily driving profile might not be suitable for the chosen configuration. By superposing all surveyed driving profiles, technical suitabilities of EVs based on the chosen infrastructure scenario can be calculated. Based on these calculations, detailed assessments as to which extent the deployment of charging infrastructure and the suitability as electric vehicle correlate are feasible. By varying the all-electrical ranges and the availability of charging infrastructure, the model has been utilized in order to assess different infrastructure scenarios. For further details on the model see [13].

\section{Scenarios for the Infrastructure Development}

In order to assess different strategies for building up charging infrastructure in Germany, 3 different scenario have been analyzed:

- the first scenario anticipates the same infrastructure development for all types of urban areas

- the second scenario varies the availability of charging infrastructure depending on the type of urban area

- the third scenario assumes only charging at home. 
TABLE 1: ASSUMPTIONS FOR THE FIRST INFRASTRUCTURE SCENARIO: PROBABILITIES FOR FINDING AN UNOCCUPIED CHARGING SPOT (IN \%)

\begin{tabular}{|c|c|c|c|c|c|c|c|c|c|c|}
\hline 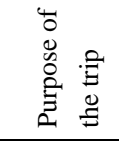 & $\begin{array}{l}\text { 혛 } \\
3\end{array}$ & 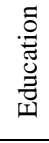 & 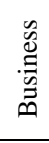 & 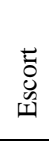 & 营 & 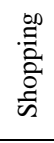 & 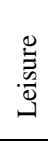 & ت્ّ & $\begin{array}{l}\text { : } \\
\text { : }\end{array}$ & 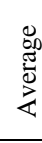 \\
\hline Stage 1 & 10 & 10 & 0 & 10 & 5 & 5 & 10 & 0 & 10 & 9 \\
\hline Stage 2 & 39 & 39 & 6 & 57 & 8 & 43 & 22 & 6 & 57 & 44 \\
\hline Stage 3 & 60 & 60 & 10 & 90 & 10 & 70 & 30 & 10 & 90 & 68 \\
\hline (Stage 4) & \multicolumn{10}{|c|}{100} \\
\hline
\end{tabular}

Table 1 shows the assumptions for finding an unoccupied charging spot at the end of the trip depending on the purpose of the trip for the first infrastructure scenario. Within the scenario, 3 different stages of progress for building up the infrastructure have been calculated. For comparison reasons, a fourth 'stage' showing $100 \%$ coverage of charging infrastructure has been calculated. Average figures represent weighted averages, based on all trips and their corresponding purposes and charging probabilities.

Fig. 1 depicts the calculation results for the first infrastructure scenario. The technical suitability as a calculation result of the superposed German driving patterns is shown for the four different stages of infrastructure development depending on the all electrical ranges of the vehicles. Additionally, the cumulative distribution function (CDF) resulting from all recorded driving patterns in the survey is shown.

This first scenario shows that increasing the availability of charging infrastructure is significantly more important than extending the all electrical ranges of the vehicles. In other words, since the slope of the curves is very flat increasing the electrical range does not have a strong effect on the suitability of the driving profiles for EVs. This holds true especially for electrical ranges larger than $100 \mathrm{~km}$. Furthermore, the figure shows that an average availability charging infrastructure of $68 \%$ nearly resembles the CDF of all German trips.

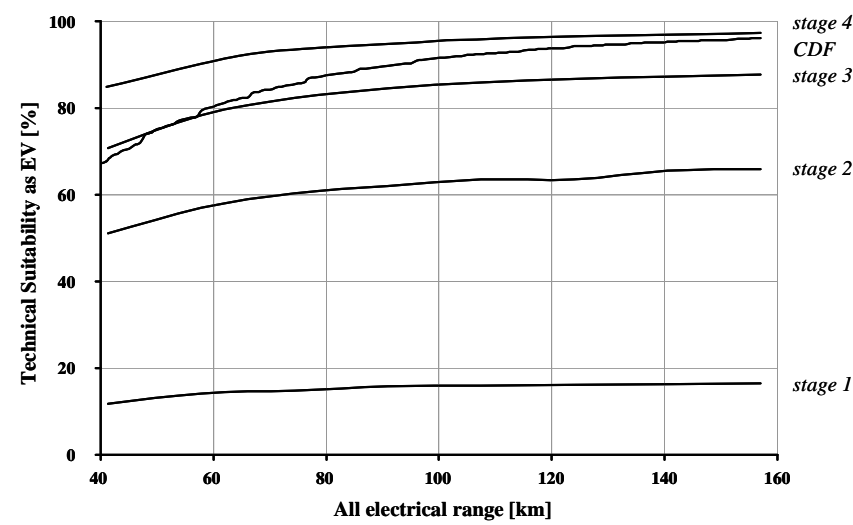

Fig. 1 Comparison of the technical suitability as EV versus all electrical ranges for the first infrastructure scenario.

The second and third infrastructure scenarios represent systematic deviations from the first scenario. In order to assess the influence of different parking behaviors in different types of urban areas and hence possibly different deployment of charging infrastructure, availabilities of 'charging at home' have been altered in the second scenario. Due to the fact that privately owned cars have a high probability of being parked at the same spot when returning home in rural areas, charging infrastructure development has been anticipated to be significantly faster in these areas compared to areas with very high population densities. Calculation results show that the variation of infrastructure being available for charging at home has a strong influence on the overall suitability for EVs. Accordingly, the third scenario focuses on this sensitivity and anticipates a rather extreme development with charging spots exclusively being available at home, i.e. no public infrastructure will be build up. For further information on the considered infrastructure scenarios see [14].

Table 2 shows exemplary results for the three different scenario calculations for an all electrical range of $124 \mathrm{~km}$ (77 mi). Mutually comparing the 3 scenarios shows that scenario 2 and 3 result in similar suitability rates. Scenarios 1 and 3 on the other hand show significant deviations. E.g., for reaching a suitability level of $87 \%$, scenario 1 needs an installed charging infrastructure of $68 \%$ (on average) compared to only $53 \%$ in scenario 3 . 53\% infrastructure availability in scenario 3 represents a complete coverage of charging at home spots. In other words, guaranteeing the possibility of charging at home for customers has the same effect as building up a semi-public / semi-private charging infrastructure with an availability of charging spots of $68 \%$ (on average). Scenario calculations for different all electrical ranges show similar results.

TABLE 2: EXEMPLARY RESULTS OF THE SUITABILITY AS EV DEPENDING ON THE WEIGHTED AVERAGE OF CHARGING INFRASTRUCTURE AVAILABILITY FOR AN ALL ELECTRICAL RANGE OF 124 KM

\begin{tabular}{|c|c|c|c|}
\hline $\begin{array}{c}\text { Weighted } \\
\text { Average }\end{array}$ & Scenario 1 & Scenario 2 & Scenario 3 \\
\hline $3 \%$ & & & $6 \%$ \\
\hline $9 \%$ & $16 \%$ & & \\
\hline $19 \%$ & & $30 \%$ & \\
\hline $30 \%$ & & $59 \%$ & \\
\hline $32 \%$ & & & $58 \%$ \\
\hline $44 \%$ & $63 \%$ & & \\
\hline $45 \%$ & & $73 \%$ & \\
\hline $53 \%$ & & & $87 \%$ \\
\hline $68 \%$ & $87 \%$ & & \\
\hline
\end{tabular}

By analyzing German driving patterns in detail and by comparing the results in different developments of charging infrastructure statements about the technical suitability of German driving patterns for electric vehicles are feasible. In order to identify critical paths towards a low carbon vehicle fleet in Germany, these results have subsequently been used in the simulation tool VECTOR21. 


\section{SCENARIOS FOR THE GERMAN VEHICLE FLEET}

As described above, the VECTOR21 model is capable of simulating the composition of the German vehicle fleet in terms of powertrain concepts based on scenario assumptions. In order to identify critical paths and significant input parameters, three different market scenarios have been calculated. Based on a business-as-usual scenario, two alternative scenarios have been simulated. Hereby, both scenarios anticipate a rather positive development of the market environment regarding electrified vehicle concepts. Eventually, by comparing the 3 different market developments, conclusions will be drawn.

\section{A. Market Scenario 1: 'Business-as-usual'}

The base scenario resembles a market development which might be interpreted as a 'best-guess-scenario“. Table 3 summarizes the assumptions made. Compared to previously calculated scenarios, these assumptions reflect a practical approach with values that might very well come true.

TABLE 3: SCENARIO ASSUMPTIONS FOR THE BUSINESS-AS-USUAL SCENARIO

\begin{tabular}{|l|c|c|c|c|c|}
\hline \multicolumn{2}{|l|}{ Scenario assumptions } & 2010 & 2020 & 2030 & 2040 \\
\hline $\begin{array}{l}\text { Oil price } \\
\text { plectricity }\end{array}$ & $€ / \mathrm{bbl}$ & 80 & 100 & 130 & 130 \\
\hline $\mathrm{H}_{2}$ price & $€ \mathrm{ct} / \mathrm{kWh}$ & 21.5 & 34.1 & 37.3 & 36.4 \\
\hline $\begin{array}{l}\mathrm{CO}_{2} \\
\text { electricity }\end{array}$ & $\mathrm{g} / \mathrm{kWh}$ & 22.3 & 39.0 & 37.6 & 36.5 \\
\hline $\mathrm{CO}_{2} \mathrm{H}_{2}$ & $\mathrm{~g} / \mathrm{kWh}$ & 648 & 510 & $\begin{array}{c}21 \\
(2025)\end{array}$ & 21 \\
\hline $\begin{array}{l}\mathrm{Charging} \\
\text { infrastr. }\end{array}$ & $\%$ & 40 & 55 & $\begin{array}{c}25 \\
(2025)\end{array}$ & 25 \\
\hline $\mathrm{H}_{2}$ infrastr. & $\%$ & 10 & 30 & 50 & 70 \\
\hline $\begin{array}{l}\mathrm{CO} \\
(\text { limits }\end{array}$ & $\mathrm{g} / \mathrm{km}$ & $\begin{array}{c}130 \\
(2015)\end{array}$ & 95 & 70 & 60 \\
\hline
\end{tabular}

Fig. 2 shows the calculation results for the entire German new vehicle fleet for the first market scenario. 2 main mechanisms can be observed: first, conventional combustion engine vehicles (gasoline \& diesel) will gradually be replaced by their hybrid versions. And second, electrified powertrains will slowly push into the market after 2020. Furthermore, up to around 2033 a relatively constant share of gasoline and gasoline hybrid vehicles can be seen. Due to the severely increased $\mathrm{CO}_{2}$-limits after this point, this share will then drop slowly. Diesel / Diesel HEVs will be pushed out of the market by alternative powertrains at the same time. The fact that Diesel vehicles will earlier drop out is due to the very expensive exhaust after-treatment for these vehicles. Nevertheless, the share of vehicles that have (some kind) of ICE will not drop under $75 \%$ in 2040 . In other words, only a quarter of all new vehicles in Germany will be propelled fully electric.

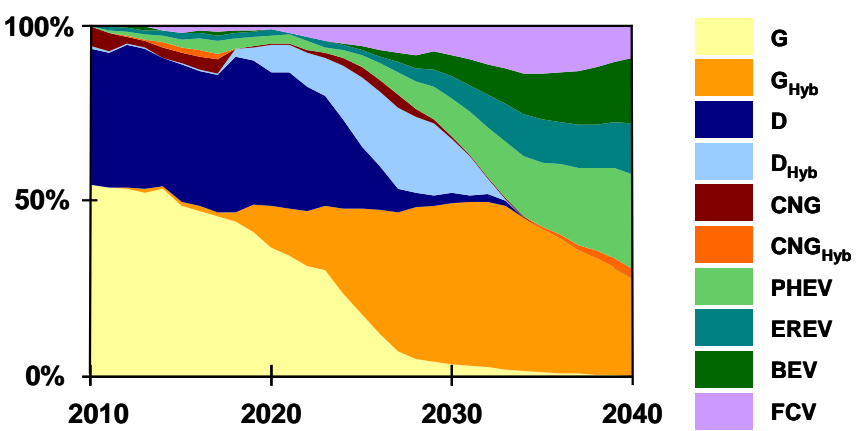

Fig. 2 Composition of the entire German new vehicle fleet in the business-asusual scenario

All three vehicle segments (small, medium, large) show similar developments. However, due to the fewer annual vehicle miles traveled, the small segment shifts slightly later and slower towards alternative drivetrains than the other 2 segments do. Mainly due to the significantly higher efficiency of electric drivetrains and by the renewable energy sources for electricity and hydrogen (from 2025 on), $\mathrm{CO}_{2}$ emissions of the German vehicle fleet will be reduced by 2 thirds in this first scenario. Fig. 3 shows the $\mathrm{CO}_{2}$ emissions for the entire German vehicle fleet (i.e. the vehicle stock and not only new purchased vehicles) differentiated into the different types of drive trains.

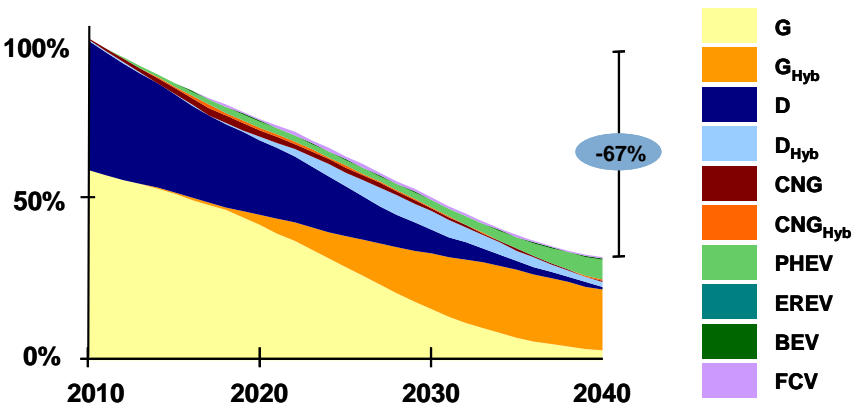

Fig. $3 \mathrm{CO}_{2}$ emissions of the entire German vehicle fleet in the first market scenario

\section{B. Market Scenario 2: 'BEV-scenario'}

As described above, 2 alternative scenarios have been calculated in order to identify critical paths for the German vehicle fleet. The first alternative scenario represents a 'BEVfriendly' scenario. The assumptions have been made having in mind a positive development of the vehicle fleet towards a high share of battery electric vehicles. The availability of both the charging infrastructure as well as $\mathrm{H}_{2}$ fueling infrastructure has been increased to $100 \%$ in 2040 (from $70 \%$ in scenario 1). Additionally, lithium ion batteries have been anticipated to develop slightly better than in the base scenario. On the on hand, costs for lithium ion batteries have been decreased to floor costs of $200 €$ per kWh (approx. 292 \$ per $\mathrm{kWh}$ ). On the other hand, assumptions regarding the fuel consumption of electrically propelled vehicles have 
been lowered by about $10 \%$. This is due to an accelerated development of energy densities of the batteries and hence more lightweight vehicles. To support a faster introduction of alternative powertrains into the market, the assumptions regarding production capacities of alternative vehicle concepts have been increased.

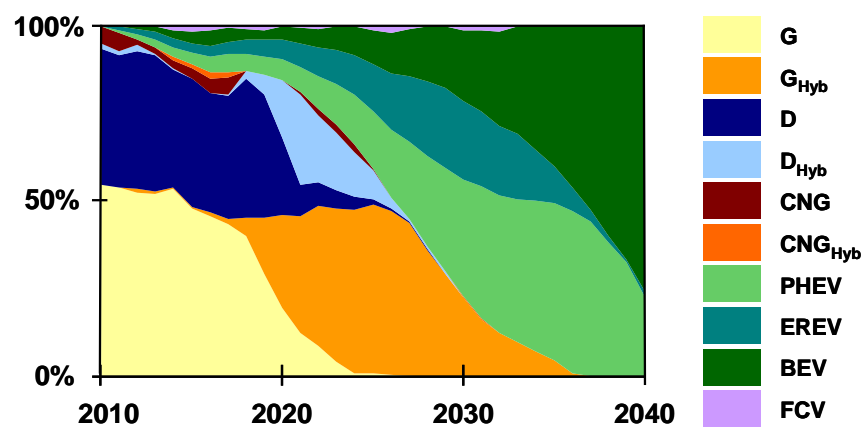

Fig. 6 Composition of the entire German new vehicle fleet in the second market scenario

Fig. 4 depicts the market development for this first alternative scenario. Additionally to the two mechanisms observed in the base scenario two further observations can be made: first, despite the increased availability of $\mathrm{H}_{2}$ fueling stations, fuel cell vehicles are not able to gain significant market shares. It seems that the positive assumptions regarding battery technologies hinder the FCV development. And second, until battery electric vehicles are able to dominate the market, PHEVs and EREVs act as an enabler for the all-electric vehicles. Declining battery costs due to high production volumes of smaller batteries, BEVs will eventually be able to gain significant market shares.

However, although this scenario has been based on very positive assumptions regarding the development of lithium ion batteries, BEVs will not be able to fully penetrate the market. Even in this rather extreme scenario it is very unlikely that up to 2040 all vehicles will be propelled fully electrically. The overall $\mathrm{CO}_{2}$ emissions of the entire German vehicle stock in this second scenario are even lower than in the first one. By 2040, $\mathrm{CO}_{2}$ emissions will drop by 3 fourths compared to the 2010 level.

\section{Market scenario 3: 'Electric mobility'}

The third scenario has also been deducted from the base scenario. It represents a slightly more positive scenario for electric mobility than the first scenario. In contrast to the second market scenario, the third scenario does not only focus on an accelerated development of battery technology, but considers different developments of all other input parameters, too. For example have the $\mathrm{CO} 2$ limits for new purchased vehicles been decreased to $50 \mathrm{~g} \mathrm{CO} 2$ per $\mathrm{km}$ on EU level. Additionally, subsidies in the amount of $4000 €$ per vehicle have been introduced for BEV and FCV in the first 5 years. PHEVs and EREVs receive half the amount. In order to put even more pressure on conventionally propelled vehicles, the oil price has been increased to $160 €$ per barrel in 2040. This third scenario not includes positive assumptions regarding battery technologies but anticipates an accelerated development for fuel cells, too. Both production costs and power densities have been slightly in- / decreased.

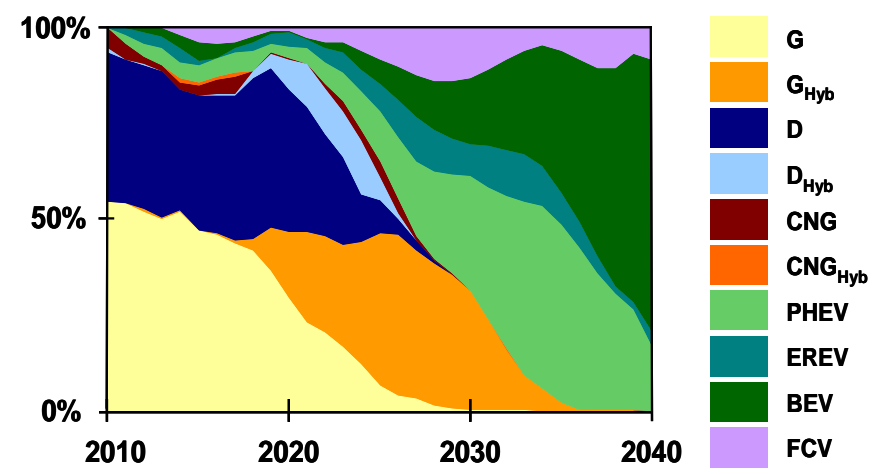

Fig. 5 Composition of the entire German new vehicle fleet in the third market scenario

As shown in Error! Reference source not found. the shift towards electrified vehicle concepts starts earlier than in the baseline scenario. Nevertheless, not all assumptions seem to have an significant impact on the new vehicle fleet. Additionally to the previously observed market mechanisms which hold true for this scenario as well - can two more developments be observed: first, in the long run, fuel cell vehicles seem to be able to conquer a sustainable niche market. This development seems sustainable and is not affected by the strongly increasing market shares of all electric vehicles. And second, the newly introduced subsidies help pushing alternative powertrains into the market in the beginning. However, this development is not sustainable. Around 2020, when government subsidies have run out and $\mathrm{CO}_{2}$ limits are not restrictive enough, electrically propelled vehicles are being pushed out of the market again. Only after 2020, when $\mathrm{CO}_{2}$ targets increase severely are alternative

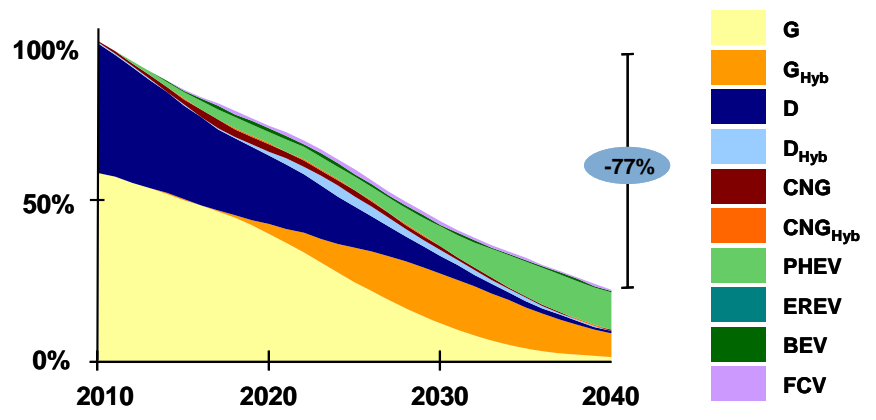

Fig. $4 \mathrm{CO}_{2}$ emissions of the entire German vehicle fleet in the third market scenario

vehicle concepts able to gain significant market shares.

The overall $\mathrm{CO}_{2}$ emissions of the entire German car fleet drop slightly lower than in BEV-scenario. Reductions of -77\% will have been reached until 2040. Error! Reference source not found. shows the development of $\mathrm{CO}_{2}$ emissions 
for the entire vehicle stock differentiated into the types of powertrains.

\section{CONCLUSIONS}

In order to identify critical paths towards a low carbon fleet in Germany, three different market scenarios have been calculated. Based on a detailed driving pattern analysis of German customers, infrastructure developments and the corresponding suitability of these driving patterns for electric vehicles have been assessed.

It has been shown that a high share of fully electric vehicles is feasible in Germany. Nevertheless, a 100\% market share of fully electrically propelled vehicles up to 2040 seems not reachable.

TABLE 4: Number of ELECTRIC VEHICLES IN THE ENTIRE GERMAN VEHICLE STOCK IN 2020

\begin{tabular}{|l|r|r|r|r|r|}
\hline $\begin{array}{l}\text { 2020 } \\
\text { 1,000 veh. }\end{array}$ & EREV & BEV & FCV & total & $\begin{array}{l}\text { German } \\
\text { goal }\end{array}$ \\
\hline Scenario 1 & 425 & 128 & 256 & 809 & \multirow{2}{*}{1,000} \\
\hline Scenario 2 & 916 & 763 & 176 & 1,855 & \\
\hline Scenario 3 & 639 & 579 & 517 & 1,735 & \\
\hline
\end{tabular}

Table 4 gives an overview on the stock of electric vehicles in Germany by 2020. Additionally, the German goal of 1 million electric vehicles on the road by 2020 is listed. The business-as-usual scenario misses this goal by nearly 200,000 vehicles. However, both alternative scenarios reach the goal very easily. The assumptions that lead to reaching this goals show that a variety of critical factors has to be considered. Both technical developments as well as political restriction are somewhat influencing the market development.

Accelerated battery developments both in terms of costs and in terms of energy densities is the most promising way on the technical side to reach the market goals. However, if only battery technology undergoes a slightly more positive development, fuel cell vehicles will not be able to gain significant market shares. In order to guarantee long term / sustainable market success of all electric vehicles, hybrid vehicles have to act as an enabler for these technologies. Especially in order to trigger learning curves and cost degressions it is essential to promote these types of powertrains.

On the political side, carefully increasing the $\mathrm{CO}_{2}$ restrictions for new purchased vehicles seems the easiest way to push alternative powertrains into the market. The goals regarding the count of EVs in the fleet might easily be reached. Furthermore, huge $\mathrm{CO}_{2}$ reductions in the entire German fleet are possible. Providing customers with monetary incentives causes a temporarily increased demand for electric vehicles. However, this development seems to be not sustainable. In order to ensure long term market success this money might be spent more efficiently in technology research and development. Table 5 summarizes the market share of electric vehicles in 2040.
TABLE 5: COMPARISON OF THE MARKET SHARES OF ELECTRIC VEHICLES (NEW PURCHASED VEHICLES) IN 2040

\begin{tabular}{|c|r|r|r|r|r|}
\hline 2040 & PHEV & EREV & BEV & FCV & \multicolumn{1}{c|}{ total } \\
\hline Scenario 1 & $27.2 \%$ & $14.6 \%$ & $18.7 \%$ & $8.8 \%$ & $69.4 \%$ \\
\hline Scenario 2 & $22.7 \%$ & $1.7 \%$ & $75.7 \%$ & $0.0 \%$ & $100.0 \%$ \\
\hline Scenario 3 & $17.4 \%$ & $3.7 \%$ & $70.5 \%$ & $8.4 \%$ & $100.0 \%$ \\
\hline
\end{tabular}

\section{ACKNOWLEDGMENT}

The The authors would like to thank the Federal Ministry of Economics and Technology in Germany for the funding of the research project "Perspectives of Electric Vehicles with high share of distributed and renewable energy sources” for which parts of the work presented in this paper will be used.

\section{REFERENCES}

[1] World Business Council for Sustainable Development (WBCSD), "Mobility 2030: Meeting the challenges to sustainability, World Business Council for Sustainable Development, 2004.

[2] European Environment Agency (EEA), "Transport and environment: on the way to a new common transport policy", Copenhagen, EEA Report No 1/2007.

[3] Deutsche Bundesregieung (German Government), "Nationaler Entwicklungsplan Elektromobilität”, August 2009.

[4] P. Mock, „Entwicklung eines Szenariomodells zur Simulation der zukünftigen Marktanteile und $\mathrm{CO}_{2}$-Emissionen von Kraftfahrzeugen“, Fakultät Konstruktions-, Produktions und Fahrzeugtechnik, Stuttgart, Universität Stuttgart, 2010.

[5] S. Schmid, P. Mock, B. Propfe, D. Hülsebusch, Market propects of electric vehicles: modelling competition of alternative and enhanced conventional vehicle technologies”, International Advanced Mobility Forum (IAMF) 2010, Geneva, March 2010.

[6] Nationale Plattform Elektromobilität (NPE), „Zweiter Bericht der Nationalen Plattform Elektromobilität“, Berlin, May 2011.

[7] Bundesnetzagentur, SAIDI (System Average Interruption Duration Index), available online under

http://www.bundesnetzagentur.de/cln_1912/DE/Sachgebiete/Elektrizita etGas/Sonderthemen/SAIDIWertStrom2009/SAIDIWertStrom2009_Ba sepage.html.

[8] TÜV Süd, Hydrogen Filling Stations Worldwide, available online under http://www.h2stations.org/.

[9] McKinsey \& Company “A portfolio of power-trains for Europe: a factbased analysis. The role of Battery Electric Vehicles, Plug-in Hybrids and Fuel Cell Electric Vehicles”, Page 7, November 2010.

[10] J. Nitsch et al., „Langfristszenarien und Strategien für den Ausbau der erneuerbaren Energien in Deutschland bei Berücksichtigung der Entwicklung in Europa und global“, Berlin, December 2010.

[11] Erdgas mobil GmbH, available online under http://www.erdgas.info/erdgaskraftstoff/tankstellen/

[12] infas Institut für angewandte Sozialwissenschaft $\mathrm{GmbH}$ and Deutsches Zentrum für Luft- und Raumfahrt e. V., Institut für Verkehrsforschung, „Mobilität in Deutschland 2008“, Haushaltsdatensatz, Bonn / Berlin, February 2010.

[13] B. Propfe, D. Luca de Tena, "Perspectives of electric vehicles: customer suitability and renewable energy integration”, 25th World Battery, Hybrid and Fuel Cell Electric Vehicle Symposium \& Exhibition, Shenzhen, November 2010.

[14] B. Propfe, S. Schmid, "Customer suitability of electric vehicles based on batterystate-of-charge analysis”, International Advanced Mobility Forum (IAMF) 2011, Geneva, March 2011. 